\title{
Antimicrobial Resistance as a Global Health Crisis FREE
}

Erik Baekkeskov, , School of Social and Political Sciences, University of Melbourne Olivier Rubin, , Department of Social Sciences and Business, Roskilde University Louise Munkholm, Department of Social Sciences and Business, Roskilde University and Wesal Zaman, Department of Social Sciences and Business, Roskilde University

https://doi.org/10.1093/acrefore/9780190228637.013.1626

Published online: 28 September 2020

\section{Summary}

Antimicrobial resistance (AMR) is a global health crisis estimated to be responsible for 700,000 yearly deaths worldwide. Since the World Health Assembly adopted a Global Action Plan on AMR in 2015, national governments in more than 120 countries have developed national action plans. Notwithstanding this progress, AMR still has limited political commitment, and existing global efforts may be too slow to counter its rise. The article presents five characteristics of the global AMR health crisis that complicate the translation from global attention to effective global initiatives. AMR is (a) a transboundary crisis that suffers from collective action problems, (b) a super wicked and creeping crisis, (c) the product of trying to solve other global threats, (d) suffering from lack of advocacy, and (e) producing distributional and ethical dilemmas. Applying these five different crisis lenses, the article reviews central global initiatives, including the Global Action Plan on AMR and the recommendations of the Interagency Coordination Group on AMR. It argues that the five crisis lenses offer useful entry points for social science analyses that further nuance the existing global governance debate of AMR as a global health crisis.

Keywords: antimicrobial resistance, antibiotic resistance, global health, global governance, transboundary crisis, collective action problem, creeping crisis, wicked problem, modernity, distributive justice, crisis analysis

\section{Dimensions of Antimicrobial Resistance}

Antimicrobial resistance (AMR) constitutes a growing threat to global health. AMR occurs when microorganisms (i.e., microbes), such as bacteria, fungi, or viruses, develop resistance to antibiotics and other chemicals that kill or inhibit them (collectively, antimicrobials) (World Health Organization [WHO], 2015). Microbes can develop resistance either spontaneously or through selective pressure from being exposed to antimicrobials (Halpern, 2009). Either way, resistant microbes are increasingly causing infections in humans and animals that are difficult to treat (Centers for Disease Control [CDC], 2020). AMR is estimated to claim at least 700,000 human lives annually worldwide and to cause healthcare system excess costs in the tens of billions of U.S. dollars (Interagency Coordination Group [IACG], 2019a; Naylor et al., 2018; 
O’Neill, 2016). Worst-case projections include 10 million annual fatalities and cumulative global costs upward of a hundred trillion U.S. dollars by 2050 (O’Neill, 2016, p. 12). The increase in AMR has stoked fears of a "post-antibiotic apocalypse," shaped by media coverage that tends to focus on apocalyptic predictions and personal tragedies (Brown \& Crawford, 2009; Nerlich, 2009). Strong uncertainties remain about numbers of infections and the associated morbidity and mortality because of a lack of reliable data (De Kraker, Stewardson, \& Harbarth, 2016). Yet annual fatalities, severe health effects, and healthcare costs have sufficed to make AMR a substantial global health crisis that has drawn attention at international and national levels, and paved the way for discussions about the need for global governance of AMR.

There is widespread agreement that human and farm animal consumption of antibiotics is the main driver of AMR (Barbosa \& Levy, 2000; Giubilini, 2017; IACG, 2019a). Since the introduction of penicillin to human therapeutics in the 1940s, bacteria have developed resistance to almost every new antibiotic developed. In the early 2010s, bacteria showing resistance to all 26 types of antibiotics then available were found in patients (Chen, Todd, Kiehlbauch, Walters, \& Kallen, 2017). Despite the risk of resistance developing, global consumption of antibiotics has increased steadily. Between 2000 and 2015, antibiotic consumption increased 65\% (expressed in defined daily doses) in 76 countries (Klein et al., 2018). In addition, the time microbes take to develop resistance to antibiotics has decreased during the decades in which such drugs have been in use (Centers for Disease Control [CDC], 2020; see also Spellberg, Bartlett, \& Gilbert, 2013). For instance, nine years passed between the antibiotic tetracycline's introduction in 1950 and the emergence of bacteria resistant to the drug, whereas resistant organisms developed within a year of the introduction of the new antibiotic Ceftaroline in 2010 (CDC, 2020).

Antimicrobials are not only used to treat and prevent infections in humans. Agricultural producers in much of the world rely heavily on antibiotics to prevent or treat diseases in their livestock or to speed up livestock growth (Kahn, 2016; Laxminarayan et al., 2016). Antibiotic use in farm animal production was introduced in the 1950s and has increased steadily across the world since. Although data on antimicrobial use in the animal sector is difficult to obtain because of poor surveillance systems in many parts of the world ( $\mathrm{Wu}, 2017, \mathrm{p} .27$ ), a minimum estimate of 60,000 tons of antibiotics (ranging up to 200,000 tons) are consumed in the livestock sector annually (Food and Agriculture Organization [FAO], 2019). This amount is expected to rise considerably in the future in response to increasing demand for meat and animal products for human consumption (Laxminarayan et al., 2016). The use of antimicrobials in food production speeds up the development of AMR by increasing the evolutionary selection pressure on microbial species. In addition, resistant bacteria and viruses can transmit between humans and animals through direct contact, the environment (soil and water), and food supply chains (Cohen, 1992; Wu, 2017).

As these patterns suggest, numerous factors beyond biology contribute to the production and propagation of AMR, including human behavioral, economic, environmental, and social forces (Littmann \& Viens, 2015, p. 209). The multidimensionality of AMR has led to increasing global agreement that AMR is one of several health threats that requires a multisectoral and multinational approach based on global coordination and actions (also known as the "One Health" approach) (WHO, FAO, \& World Organization for Animal Health [OIE], 2015). Although the need for global coordination to fight AMR might seem obvious, AMR is difficult 
to address at the global level because of the complex and multifaceted nature of the problem. Indeed, the IACG's 2019 report to the UN secretary general states that AMR is faced with inadequate political commitment and that existing global efforts "are currently too slow and must be accelerated" (IACG, 2019a, p. 6). The complexity of AMR impedes a strong global governance regime, and current (as of 2019) global initiatives consist mostly of broad aims and guidelines rather than formal treaties with binding obligations and quantifiable targets. In legal terms, they constitute soft international law rather than hard law instruments (Guzman \& Meyer, 2010). This article addresses some of this complexity by outlining five sociopolitical characteristics that shape the political actions necessary to curb the threat. The authors of this article believe that applying this sociopolitical perspective on the global health crisis is instrumental in allowing researchers to engage more broadly with political science and policy theory within the field of AMR.

The remainder of the article begins by describing "Five Crisis Lenses for Characterizing the AMR Threat" that reveal the sociopolitical characteristics impeding attempts to formulate and implement effective global initiatives against AMR. It then proceeds to describe central "Global Responses to AMR" and how these are shaped by the characteristics. The last section looks at the existing "Social Science Research on AMR as a Global Crisis." In the "Conclusion," the article deduces that the five crisis lenses offer useful entry points for social science research to further nuance the global governance debate on AMR as a global health crisis and to systematically address broader sociopolitical issues than global responders have hitherto tended to consider.

\section{Five Crisis Lenses for Characterizing the AMR Threat}

Although AMR is easy to recognize as a biomedical problem, it also interacts with social issues and dilemmas. This section demonstrates that AMR can be understood in more detail by using key social science lenses that have helped to describe similar types of global threats, such as climate change, pandemics, and ozone depletion. It argues that AMR combines five sociopolitical problems or crises, which can impede effective actions at the global level: (a) transboundary and collective action problems and (b) super wicked and creeping problems, and crises of (c) modernity, (d) advocacy, and (e) distributive justice. In turn, research on AMR can potentially contribute to deeper understanding of these five general types of public problems or crises.

\section{AMR as a Transboundary and Collective Action Problem}

Although humankind has always faced crises, the surge in transboundary crises is a phenomenon inherent to increased interconnectedness and globalization (Boin, 2009; Boin, Rhinard, \& Ekengren, 2014; Hermann \& Dayton, 2009). Transboundary crises are characterized not only by their cross-border impacts but also by the fact that solutions demand cross-national cooperation. They are also multisectoral, crossing institutional and epistemological boundaries. Responding to transboundary crises often outstrips the capacity of nation-states and established national bureaucracies, and poses significant challenges not just to national governments but also to multinational actors. In essence, such crises "affect multiple jurisdictions, undermine the functioning of various political sectors and critical 
infrastructures, escalate rapidly and morph along the way" (Ansell, Boin, \& Keller, 2010, p. 195). In turn, AMR is clearly a transboundary crisis. Like other crises of this kind, such as climate change, pandemics, and ozone depletion, AMR spreads from one jurisdiction to the next, and responding to it involves many kinds of actors and authority in any given jurisdiction.

Using the transboundary lens on AMR highlights the interdependency of jurisdictions and actors affected by the crisis. Because resistant microbes tend to spread across national borders, and because single bureaucracies are generally unable to effectively mitigate the problem, governments and affected actors depend on one another to address it. That is, they often need to pool their resources and divide the labor of acting against AMR between them (Ansell et al., 2010). Hence, AMR cannot be solved by human health agencies alone, but requires action across human and animal health as well as agriculture and environmental portfolios. And to suppress new AMR and prevent spread, many countries need to act in ways that effectively mitigate AMR within their boundaries. Existing global and national initiatives against AMR have recognized its transboundary dynamics by adopting a "One Health" approach to the crisis (WHO, FAO, \& OIE, 2015). In line with the transboundary crisis concept, the core One Health insight is that human, animal, and environmental health can be interdependent. Taking a One Health approach to AMR means accepting that effective response depends on coordinated international and multisectoral action. The approach thus calls for governments and other actors affected by AMR to take actions and coordinate them across national and sectoral boundaries.

Achieving policy coordination among domestic actors and between countries is not trivial, however. That is, it suffers from collective action problems. Coordination failures can be caused by conflicting interests, free riding, or the tragedy of the commons (Hardin, 1968; Olson, 1965). There are multiple and potentially conflicting interests involved in producing and curbing AMR, such as those of agriculture, medical professionals, and pharmaceutical producers (Kahn, 2016). In addition, AMR responses provide opportunities for some countries to free ride on others' costly policies and programs. Finally, benefits from using antimicrobials are local, whereas the costs of AMR are global, making AMR a tragedy of the commons (Hollis \& Maybarduk, 2015; Laxminarayan, 2016). These issues mean that autonomous actors and sovereign countries pursuing their own interests have weak incentives to act against AMR, even though they collectively stand to gain from maintaining effective antimicrobials.

\section{AMR as a Super Wicked and Creeping Problem}

The transboundary dynamics of AMR makes the global crisis complex. Indeed, AMR satisfies the four criteria of super wicked problems (Levin, Cashore, Bernstein, \& Auld, 2012): (a) time is running out to curb AMR because new development of antimicrobials has generally halted while the consumption of such agents keeps increasing; (b) medical and other technical advances simultaneously cause the problem while also being deployed to provide a solution, such as investments in new drug development and regulations to alter prescriber behaviors; (c) the central authority needed to address AMR is weak or non-existent because the crisis is transboundary and because international authority depends entirely on the willingness and collaboration of sovereign states; and (d) irrational discounting has occurred in the many decades that AMR has been known, pushing responses into the future because more 
immediate and visible issues occupied political agendas and policy makers. These features bias governance responses to short-term time horizons rather than toward longer-term collective interests, because "even though we collectively recognize the need to act now to avoid future catastrophic impacts, the immediate implications of required behavioural changes overwhelm the ability of the political and policy systems at multiple levels to respond" (Levin et al., 2012, p. 129).

AMR resembles not just a super wicked problem but also a creeping crisis. Such crises build up slowly over many years without generating much government response because they tend to slip under the radar of politicians who are preoccupied with more immediate issues; their creeping character makes them notoriously difficult to put (and keep) on the political agenda (Boin, 2004; McConnell, 2003). As described by Scott Podolsky (2018), a few highly developed countries began to make policies in response to AMR between the 1970s and the 1990s. But global political attention to AMR only became evident much later, from 2013 and onward.

Super wicked problems and creeping crises often lead to political inaction. Aside from the global coordination challenges of collective action, these types of crises tend to receive limited political attention even at the national level. They are complex and lack condensed dramatic events that draw immediate public attention. Simple solutions are not readily available and are likely to consist of a stream of policies and programs that stretch for decades. This implies that the political rewards of responding to them are modest, although the political costs can be high. Politicians are rarely rewarded electorally for responding effectively to a health crisis, but they are likely to be punished for mismanaging the crisis by either overreaching or underestimating the response (Boin, McConnell, \& Hart, 2008; Rubin, 2018). Not only are politicians rarely rewarded electorally for a non-event (the lack of a health crisis), they also need to defend what seem like policy inefficiencies over many years in anticipation of a possible disaster in the future. That is, the price of addressing the problem will be paid now, but the benefits will be reaped in the future, setting up few political advantages to implementing preventive measures despite obvious humanitarian benefits. In the case of AMR, for example, government investments in developing new varieties of antibiotics incur costs in the present, but new treatments will not arrive until an uncertain date in the future.

\section{AMR as a Crisis of Modernity}

Ulrich Beck's Risk Society (1992) pioneered the view that major risks are becoming endogenous to modern society. Scholars and practitioners have increasingly recognized that crises have become parts of modernity itself, for instance, in the form of pollution, industrial calamities, transport accidents, and other disasters that originate in technology and human society (hence, the emergence of an Anthropocene age). This endogeneity contains a duality. People expect modern societies to shield them from risks and crises of all kinds, and some global risks and crises are themselves produced by modernity. Modernity's risk endogeneity helps to deepen understanding of the previously mentioned wicked overlap between AMR producers and responders, and to see its wider connections. 
Citizens in contemporary societies tend to expect protection from disturbances (e.g., Ansell, 2019). Fire and police departments, welfare policies, public healthcare facilities, occupational health and safety regulations, and civil defense agencies all represent government or collective institutions that emerged alongside, and often as parts of, the modern state. Research and development to generate new medical treatments (such as antibiotics), medicines regulation, certifications of professionals, and guidelines for proper medical treatment are parts of the large and ever-growing corpus of government efforts and guarantees that make and keep citizens safe.

In turn, obesity, climate change, and AMR are the (unexpected) effects of deploying technologies that reduce hunger, spur industrial development, and treat infectious diseases, respectively. Obesity rises as people gain access to abundant calorie sources produced through modern agricultural methods and food manufacturing. Climate change results from gases released by the modern world's growing number of industrial facilities, transportation vehicles, and other polluters. AMR is the result of biological evolution brought about by humanity's increasing use of antimicrobial agents. That is, these major crises are consequences of progress in other areas of modern life. Investments in new drug development, new certification criteria, and new regulations and guidelines can be and are now being deployed in response to AMR; but these were also the instruments of modernity that created the AMR crisis in the first place.

Modernity's risks are often not "perceptible to the senses . . the risks of the civilization of today typically escape perception and are localized in the sphere of physical and chemical formulas (e.g. toxins in foodstuffs or the nuclear threat)" (Beck, 1992, p. 21). The fact that the risks in modern societies escape our perception entails that experts and expert communities play a crucial role as discoverers or interpreters of risks. This holds particularly true for AMR because detecting microbial developments or the risks that AMR poses to the economy, health, and other layers of everyday life requires high specialization and sophisticated techniques. AMR's place as a crisis of modernity further undermines the political rewards of dealing with it. When voters have difficulty perceiving the threat unless it is mediated by experts, the benefits will often be equally invisible to the layman. The public is likely to be skeptical (in the vein of climate change deniers), and the successes of AMR responses are not easily communicated. Counterfactual fatality estimates (in the absence of timely interventions, how many would have died?) long after the implementation of policies are not likely to sway many voters.

\section{AMR as an Advocacy Crisis}

Comparison to other global crises illustrates that the fight against AMR has relatively limited support from national and transnational advocacy coalitions and the general public. The ongoing climate change crisis shares many similarities with AMR. It is also a transboundary, super wicked, and creeping crisis that is endogenous to modern society. Hence, many scholars have compared the global dynamics of the two crises and highlighted their similarities, despite one primarily being an environmental crisis and the other a health crisis (Padiyara, Inoue, \& Sprenger, 2018; Rizvi \& Hoffman, 2015; Rochford et al., 2018). However, there is substantially more advocacy network and general public engagement with climate change than with AMR. Climate change is popularly recognized as one of the most important global 
threats. According to a 26-nation survey conducted by Pew Research Center, people, on average, rank climate change as the most important international threat and rank it as the most important threat in half the surveyed countries (Poushter \& Huang, 2019). By contrast, AMR did not appear at all on the ranked list of international threats.

Hundreds of major transnational NGOs advocate for curbing climate change. A few examples are Greenpeace, the World Wildlife Fund, the Sierra Club, and Oxfam. There are even more national nongovernmental organizations (NGOs) and civil society organizations. More than 2,000 NGOs have been admitted by the Conference of the Parties as observers to the United Nations Framework Convention on Climate Change (UNFCCC, n.d.). Several countries have "green" parties that were originally founded to raise and fight for environmental issues in general and climate change in particular; and most democracies have political parties that include climate change as a substantial part of their platform. Climate change figures prominently in the UN's Sustainable Development Goals for 2030 (Jasovský, Littmann, Zorzet, \& Cars, 2016; UN, 2015), but AMR is not even mentioned (though it arguably contributes to some of them; WHO, FAO, \& OIE, 2015).

By contrast, global agenda setting for AMR has been almost exclusively driven by health agencies, with little participation from transnational advocacy networks or civil society coalitions. This is likely to be a significant shortcoming because solutions to creeping and complex crises are particularly dependent on such agenda-setting policy entrepreneurs and advocacy networks (Carpenter, 2007; Kingdon, 2014). NGOs and other advocates ensure that an issue will figure on the global political agenda even in the absence of national political attention and sluggish diplomatic processes. Thus, AMR has a relative lack of broad-based global advocacy to push it to the forefront of global attention.

Finally, AMR can be difficult to understand, which may further explain the issue's relatively low levels of public salience. Antimicrobials and resistance are characterized by widespread public misconceptions and myths (O’Neill, 2016; WHO, 2015). A 2015 WHO survey suggests that a substantial share of the world's population has never heard the terms "antibiotic resistance" or "antimicrobial resistance," that many people believe that antibiotics can cure viruses such as cold and flu, that only those who use antibiotics regularly are at risk of antibiotic resistance, and that there is nothing individuals can do to lower the risk of AMR (WHO, 2015). Hence, many people misunderstand how to use antimicrobials and are unaware of or misunderstand the link between their behaviors and consequences such as AMR. Without an advocacy network and the broader communication logics that boundary spanners can use, the AMR discourse may continue to have difficulty translating from what Weingart, Engels, \& Pansegrau (2000) have called the "science sphere" to the "political" and "mass media" or "public" spheres.

\section{AMR as a Distributive Justice Crisis}

AMR has different impacts and solutions across countries. Of particular distributional consequence is the distinction between high-income countries (HICs) and lower- and middleincome countries (LMICs). In HICs, providing incentives for patients, doctors, and farmers to reduce their use of antibiotics might constitute the most effective AMR solution. High rates of antibiotic consumption are closely related to expectations of patients and health professionals 
about antibiotic prescribing (Jensen, Nielsen, \& Fynbo, 2019; Laxminarayan et al., 2013). For instance, several studies of day-to-day interactions between doctors and patients show that massive overconsumption is often a consequence of overprescribing by doctors who recommend antibiotics for viral infections because of pressure from patients who want immediate relief from their suffering (Broom, Broom, Kirby, \& Adams, 2016; Filippini, Ortiz, \& Masieri, 2013; Jensen et al., 2019).

Yet HICs are relatively small contributors to the AMR problem. Fast-growing LMIC economies such as Brazil, Russia, India, China, and South Africa accounted for three-quarters of the increase in antibiotic consumption between 2000 and 2010 (Laxminarayan et al., 2016, p. 168). LMICs as a group also have the highest antimicrobial consumption and AMR prevalence. Several studies of AMR in LMICs have identified fundamental drivers of AMR that are linked to contextual structures rather than individual behaviors (Alsan et al., 2017; Gartin, Brewis, \& Schwartz, 2010; Graham, Giesen, \& Buntz, 2019; Laxminarayan et al., 2016; Okeke et al., 2005). Dirty drinking water and overcrowded housing expose people to more diseases. Poorly functioning or difficult-to-access healthcare drives people toward the promise of "quick fixes" such as antibiotics. High prices or low quality of such medicines drive people to consume fewer doses than they actually need in order to cure the disease; this, in turn, enables resistant microbes to develop and survive. Changing prescriptions has little impact because local pharmacies sell antimicrobials over the counter, and Internet retailers offer easy and direct access for consumers (Sakeena, Bennett, \& McLachlan, 2018; see also Laxminarayan et al., 2013). Achieving effective AMR responses is therefore closely linked to general economic and political development. Globally, this means that the most costly and difficult interventions against AMR must be borne by countries and regions that are least capable of carrying them.

The legacy of antimicrobial overconsumption in some places and times leaves those in other places and later times with less effective antimicrobials and much more costly treatments. At the extreme, these others are left without medications for microbial infections (impoverished human medicine) and with livestock that frequently falls prey to diseases (less food security). Hence, AMR has implications for intergenerational and intragenerational justice (Millar, 2011). This raises a number of ethical concerns (Coast \& Smith, 2015; Daulaire, Bang, Tomson, Kalyango, \& Cars, 2015; Littmann \& Viens, 2015; Millar, 2011; West-Oram \& Buyx, 2017). Ensuring that there is equal access to effective treatments of microbial infections now and in the future arguably requires that all countries accept constraints on use (Millar, 2011, p. 155). But equal constraints would not resolve the previously discussed inequity of responses between countries and regions. For instance, populations in HICs and the most developed LMICs are the primary beneficiaries of restricting antimicrobial consumption, while populations in poorer LMICs chiefly benefit from increased access to antimicrobials (Millar, 2011; Rollin, 2001). Hence, achieving global solidarity relies on global settlements over how to pursue just distributions of existing and new antimicrobials and how to develop just burden-sharing mechanisms.

The following sections, "Global Responses to AMR" and "Social Science Research on AMR as a Global Crisis," analyze central global initiatives developed to mitigate AMR in light of the five crisis lenses, and discuss different global governance approaches to curbing AMR. 


\section{Global Responses to AMR}

Biological and epidemiological sciences have studied microbes' development of resistance to antimicrobial agents since the early part of the 20th century. Yet global governance responses to AMR as a crisis only began to gain momentum much later. In his authoritative historical account of AMR, Scott Podolsky (2018) identifies the period from 2013 to his present (i.e., 2018) as particularly important in setting the issue on the global agenda for political action. A handful of countries began from the 1970s and onward to make policies to restrict and regulate antibiotic use, as well as to raise healthcare professionals' and public awareness about appropriate uses of such medications. But while highly successful in curbing AMR, these efforts were mostly made by small to medium-sized states in Northern Europe (Podolsky, 2018). The intervening decades have seen growing agreement among public health experts and professionals that mitigating AMR requires coordinated and collective global action (Anomaly, 2010; Hoffman \& Ottersen, 2015; Kades, 2005; Laxminarayan et al., 2013; Rizvi \& Hoffman, 2015).

Podolsky (2018) argues that the pivotal event in global agenda setting for AMR was a report to the UK government by Sally Davies, then the UK's chief medical officer (2013). Davies equated AMR to climate change, and the report set off a chain of events that culminated in two specific global initiatives: the Global Action Plan (GAP) endorsed through the World Health Assembly in 2015 and the Political Declaration on Antimicrobial Resistance adopted by the UN General Assembly in 2016.

The GAP lists five strategic objectives. These include improving awareness and understanding of AMR through effective communication, education, and training; strengthening situational information through surveillance and research; reducing infection incidences through infection control and hygiene measures; better and more appropriate use of antimicrobials; and developing sustainable investment in new medicines, diagnostic tools, vaccines, and other interventions (WHO, FAO, \& OIE, 2015). The WHO Member States (194 countries) endorsed the GAP through the World Health Assembly in May 2015, thereby committing themselves to developing multisectoral national action plans within two years (WHO, FAO, \& OIE, 2015, p. 5). By 2018, 100 countries had developed national action plans to combat AMR, while 51 other countries had national action plans under development (WHO, FAO, \& OIE, 2018). Hence, the three UN agencies collaborating on AMR response (the World Health Organization [WHO], the Food and Agriculture Organization [FAO], and the World Organization for Animal Health [OIE]) reported that "progress has been sustained" even if the timeline had slipped (WHO, FAO, \& OIE, 2018, p. 1).

In September 2016, the UN General Assembly convened a high-level meeting for Member States, nongovernmental organizations (NGOs), civil society, the private sector, and academic institutions to highlight the global public health threat of AMR. Outcomes were a "Political Declaration on Antimicrobial Resistance" and the creation of the Interagency Coordination Group on Antimicrobial Resistance (IACG) (United Nations General Assembly [UNGA], 2016). The IACG has the mandate to "provide guidance for approaches needed to ensure sustained effective global action to address antimicrobial resistance" in collaboration with WHO, FAO, and OIE (WHO, 2019). In July 2018, the IACG presented its first Discussion Paper on "Future Global Governance for Antimicrobial Resistance" (IACG, 2018). The discussion paper presents 
a model for building a strong global governance regime based on "a global multi-stakeholder agreement-such as a treaty-within the next 10 years," a High-Level Commission with "no more than 10 heads of state and senior directors from other sectors," a Global Steering Board and a Standing Secretariat (IACG, 2018, pp. 8-10).

In January 2019, the IACG invited stakeholders to provide written feedback on its "Draft Recommendations" (IACG, 2019b). After receiving comments on the draft from more than 500 stakeholders, including representatives of Member States, civil society organizations, private sector groups, international organizations, and individuals and others, the IACG finalized and submitted its report "No Time to Wait: Securing the future from drug-resistant infections" to the UN General Assembly in April 2019. The final report does not repeat the idea of a treaty but suggests instead "that priority be given to adopting and implementing global standards and best practices" (IACG, 2019a, p. 23). It also recommends establishing a "One Health Global Leadership Group on Antimicrobial Resistance" supported by a Joint Secretariat managed by the tripartite WHO, FAO, and OIE group (IACG 2019a, p. 21). Further, the final report emphasizes delegating specific responsibilities to international organizations, governments, civil society organizations, industries, and other stakeholders. Member States are called on to ensure access to antimicrobials as well as to alternatives such as vaccines and diagnostics, while public and private donors are called on to increase investment, innovation, and research, and civil society groups and organizations are called on to engage systematically and meaningfully as key stakeholders in the One Health response to AMR at global and other levels (IACG, 2019a, p. 2). Table 1 summarizes these key global initiatives since the GAP was issued in 2015, and their objectives.

Table 1. Key Global Initiatives Against AMR Since 2015

\section{Year Initiative Objectives}

\section{Global Action Plan on Antimicrobial Resistance (GAP)}

- World Health Organization (WHO)

- Food and Agriculture Organization of the United Nations (FAO)

- - World

Organization for Animal Health (OIE)
- Improve awareness and understanding of antimicrobial resistance through effective communication, education and training

- Strengthen the knowledge and evidence base through surveillance and research

- Reduce the incidence of infection through effective sanitation, hygiene and infection prevention measures

- Optimize the use of antimicrobial medicines in human and animal health

- Develop the economic case for sustainable investment that takes account of the needs of all countries, and increase investment in new medicines, diagnostic tools, vaccines and other interventions 


\section{Political Declaration on Antimicrobial \\ Resistance \\ - United Nations Secretary-General \\ (UNSG)}

- Establish the Interagency Coordination Group on Antimicrobial Resistance (IACG), providing practical guidance for approaches needed to ensure sustained effective global action to address AMR
2018 Future Global

Governance for

Antimicrobial

Resistance: IACG

Discussion Paper

- IACG
- Promote and support a One Health Approach to AMR

- Strengthen existing systems and mainstream efforts to combat AMR so as to leverage gains across the SDGs

- Catalyze the implementation of earlier recommendations by addressing key gaps and bottlenecks in the current response to antimicrobial resistance

- Present recommendations that are practical and feasible implement, and that support a targeted response based on country context

2019 No Time to Wait: Securing the Future From Drug-Resistant Infections

- IACG
- Emphasize the importance of building and sustaining effective and tailored national responses to address antimicrobial resistance through increased political commitment and more coordinated multisectoral efforts across the One Health spectrum, while also leveraging gains across the SDGs.

- Promote equitable and affordable access to and stewardship of new health products, through both existing and future global access initiatives.

- Strengthen the systematic engagement of civil society and the private sector to optimize their contributions to the response to AMR, including working with national governments

- Emphasize the need for innovative approaches to mainstream AMR-related activities and leverage resources from existing funding streams, as well as to mobilize new and additional funding.

- Promote the creation of a platform that will be instrumental in raising the profile and urgency of addressing AMR, building and maintaining 
political momentum and public support, enabling more comprehensive monitoring of the science and evidence related to antimicrobial resistance, ensuring accountability among all stakeholders and recognizing the central role of national governments.

\section{Social Science Research on AMR as a Global Crisis}

Although adverse social consequences of AMR are increasingly apparent and global solutions being pushed with some urgency, social science research investigating these consequences and solutions has been limited. Generally, social scientific engagement with AMR has been far more limited than physical and life and medical scientific engagement. A search in the Social Sciences Citation Index (SSCI) using the search terms "antimicrobial resistance" OR "antibiotic resistance" in the articles' topics shows that between 1956 and 2018, just more than 1,300 social science articles had been published on the topic. As a comparison, the same search in the overall Web of Sciences, including medical and physical and life science journals, yielded more than 60,000 articles.

The majority of social scientific contributions on AMR apply individual or organizational analytical perspectives rather than national or global perspectives. They investigate the individual patient or prescriber behaviors, organizational management in hospitals, farms, veterinary clinics, and pharmaceutical businesses related to antimicrobials (e.g., Bosley, Henshall, Appleton, \& Jackson, 2018; Gartin et al., 2010; Jensen \& Andersen, 2015; Jensen et al., 2019; Kamenshchikova, Wollfs, Hoebe, Penders, \& Horstman, 2018; Zubair \& Hussain, 2018). Research that investigates local drivers and effects of AMR, such as prescriber practices at hospital and clinical levels, provides many valuable inputs for managerial decision-making. However, global policy decision-making and implementation relies on more than generating behavioral effects and organizational incentives. There is a need to also understand the policy and outcome dynamics at the global level. Yet, only a very small number of the articles identified in the SSCI investigates AMR as a global health crisis with focus on global implications and global solutions. Global political Boolean search terms in SSCI only produces limited hits: "antimicrobial resistance AND global crisis" among SSCI article topics yields just two hits; "antimicrobial resistance AND global health crisis" only produces one hit; "antimicrobial resistance AND security" returns 25 hits; and "antimicrobial resistance AND global governance" only results in five hits. Hence, current literature offers much less insight about AMR as a global health crisis than as a local or organizational crisis. Substantial potential remains for social science research on AMR that investigates the social processes and forces at the global level.

Focusing on the global governance literature that does exist on AMR, some important scholarly debates can be discerned about initiatives to curb AMR. To a limited extent, these debates mirror the five crisis lenses discussed previously. Discernible, in particular, is concerns for distributive justice problems and the transboundary character of AMR. 
Reflecting on how to improve the distributive justice of AMR, Littmann and Viens (2015, p. 212) emphasize that "the global burden of infectious disease is distributed highly unevenly and low-income countries are disproportionately affected by AMR." This implies that HICs should bear most of the burden of effective global stewardship of AMR by financing research into new drugs and technologies, as well as by enhancing surveillance and reporting systems. As a concrete suggestion, Anomaly (2010) argues that a global treaty on antibiotics could be based on "the benefit principle, which holds that a nation should contribute to a collective endeavor in proportion to its expected benefit" (Anomaly, 2010, p. 19). This assumes that the nations that are likely to benefit most from a treaty will be willing to pay higher costs compared to those who will have fewer benefits from a treaty. Wealthier countries might wish to fund a global surveillance system to track the evolution and spread of AMR, or be willing to donate new diagnostic technologies to poor nations to improve treatment of infectious diseases (Anomaly, 2010, p. 20). These distributional considerations could be seen as isolated ethical dilemmas, but they have direct repercussions for the prospect of setting up an effective system of global governance: the distributional consequences (in terms of responsibility, impacts, and costs) might need to be addressed to ensure that many countries take actions against AMR.

The transboundary character of AMR and the associated collective action problems have made several scholars raising concerns regarding whether the global responses to AMR are ambitious enough to effectively address these issues (e.g., Aguirre, 2017; Behdinan, Hoffman, \& Piercy, 2015; Daulaire et al., 2015; Hey \& Kesselheim, 2017; Hoffman \& Outterson, 2015; Padiyara et al., 2018; Rochford et al., 2018; So et al., 2010; Spellberg et al., 2013). A key tension exists between support for current global AMR governance using a "soft international law" approach, emphasizing information sharing, recommendations, and guidelines; and advocates of a "hard international law" approach, which calls for political action in the form of binding international treaties (e.g., Anomaly, 2010; Hoffman, Røttingen, \& Frenk, 2015; Hoffman \& Ottersen, 2015; Kades, 2005; Padiyara et al., 2018; Rizvi \& Hoffman, 2015).

Advocating for the hard law approach, Hoffman et al. (2015) uses four assertions about AMR and international politics to argue in favor of international legal interventions. Firstly, AMR is a problem that has a significant transnational dimension, meaning that it involves multiple states, transcends national borders, and transfers risks of harm or benefit across countries. Secondly, it justifies the use of an instrument with coercive features to resolve the collection action problem. Thirdly, there is a reasonable chance of achieving benefits because those in power have an incentive to act. Finally, international legal intervention is a stronger commitment mechanism than other tools available, such as "political declarations, codes of practices and institutional reforms" (Hoffman et al., 2015, p. 66). Drawing on the past experiences with previous global health treaties as well as research on treaty effectiveness in general, Padiyara et al. stop short of dismissing nonbinding mechanisms but conclude that the "strong, swift, and coordinated action needed to address rising rates of AMR will be better served through legally binding governance mechanisms" (Padiyara et al., 2018, p. 2). Similarly, O'Neill (2016) concludes that a supra-national entity modeled on past successes can direct funding toward innovation in antimicrobials. AMR stakeholders, in a joint declaration published in the Lancet, also emphasize the need for binding legal agreements and establishing a novel supranational entity to facilitate such agreements (Rochford et al., 2018). 
Arguments like these suggest that an international treaty could establish a strong global governance regime capable of punishing free riding, redistributing gains and costs, and facilitating cooperation across divergent national and sectoral interests.

Thus, hard law is most often proposed as the panacea for dealing with AMR at the global level. However, most proposals for international treaties fail to consider the mixed empirical experience from binding agreements that deal with similar global threats. One key lesson to take away from the international efforts to curtail climate change, for example, is that binding commitments might not be very effective. Not only did some key states opt out of these climate treaties, but even the pinnacle of global governance efforts, the 1997 Kyoto protocol, only had 37 industrialized countries actually committed to legally binding reductions in emissions, and they have mixed results to show for it (Shishlov, Morel, \& Bellassen, 2016). Another example is the 1972 Biological Weapons Convention prohibiting the use of biological weapons. The Convention falls short on verification provisions and lacks an intergovernmental organization in charge of implementation and enforcement-shortcomings that make it weakly equipped to facilitate global disarmament in practice (Zanders \& Smithson, 2011). The issue of verification - the ability to detect violation of a treaty's limits in sufficient time to mount an appropriate response (Zanders \& Smithson, 2011, p. 480)-is not addressed by those advocating for hard law to deal with AMR. In fact, much more research is needed on how international treaties to combat the emergence and spread of AMR would be formulated, implemented and executed in practice.

In addition, there are theoretical grounds to question whether a hard law approach would more effectively overcome AMR's collective action problems (Ostrom, 2010; Wendt, 1994). Ostrom (2010) argues that a single governance unit is poorly suited to solving global collective-action problems in situations where-as is the case with AMR-global governance relies heavily on national, regional, and local efforts. Instead, Ostrom recommends polycentric governance where a system of multiple governing authorities at differing scales (rather than a monocentric global unit) draw on local knowledge, mutual monitoring, and network learning. Polycentric governance is easier to implement as both the initiative and implementing capacity originate from the same bottom-up network of subnational stakeholders. An example of a successful polycentric governance system is the C40 Cities, a network of 94 megacities committed to addressing climate change that by some measures is delivering $30 \%$ of all climate change action (C40 Cities, n.d.). A similar global network could link major national healthcare facilities or centers committed to addressing AMR.

Beyond overcoming free riding and other collective action problems, existing "soft" global governance systems, such as the GAP-inspired National Action Plans on AMR that more than 100 countries had signed by the end of 2018, might also facilitate the necessary buy-in from countries whose needs are not well served by a uniform global treaty. Because AMR is driven by different fundamental factors in different contexts, the most effective global response may be simultaneous but tailored national and local policies (e.g., Dixon \& Macdonald, 2018; Högberg, Heddini, \& Cars, 2010). As previously described, AMR response in HICs can target antimicrobial consumption behaviors, whereas creating access to high-quality antibiotics is more effective in many LMICs (almost 6 million deaths annually in these countries can be attributed to the lack of access to antibiotics; Rochford et al., 2018). "Soft" global governance of AMR may spur countries to act and provide useful guidance for national and local initiatives without imposing expensive and ineffectual obligations. 
Worth noting is that the 2019 IACG final report seems to balance the hard and soft law approaches to global AMR governance. Its objectives (Table 1) clearly aim at further strengthening the global governance of AMR, but they do not include a call for a treaty with binding agreements. Instead, the IACG noticeably recommends establishing new supranational agencies such as the One Health Global Leadership Group on AMR and the Independent Panel on Evidence for Action against AMR (inspired by the Intergovernmental Panel on Climate Change).

\section{Conclusion}

AMR has increasingly been conceived of as a global health crisis since the early 2010s. International declarations and reports authored jointly by human health, veterinary, and agricultural agencies emphasize that mitigating and curbing the emergence and transmission of AMR requires global coordination and actions in every country and many sectors. Yet such efforts reach beyond biological, medical, and epidemiological understandings into the dynamics of politics, governance, and society. Hence, this article has outlined five sociopolitical lenses that help in understanding AMR as a global health crisis beyond its biological and medical implications. First, AMR is a transboundary crisis that entails collective action problems globally and across sectors. Second, AMR is a creeping and super-wicked problem that is inherently difficult to set and keep on political agendas. Third, AMR is a crisis of modernity because it emerges from solutions to other health and food security problems. Fourth, AMR is an advocacy crisis because the issue has not fully penetrated broader public and political discourses and agendas. Fifth, AMR is a distributive justice crisis because it contains strong intergenerational (between future generations and existing ones) and intragenerational (between different regions) inequities and dilemmas.

So far, social science research on AMR has generally focused on individual patient or prescriber behaviors and organizational management in hospitals, farms, veterinary clinics, and pharmaceutical businesses. Few scholarly studies have addressed AMR as a global issue. Those that have tend to address the distributional and collective action consequences of AMR, emphasizing global "hard law" to overcome collective inaction and redistribution to create equitable access to medicine and animal protein. The five crisis lenses reveal that social science research on AMR can be considerably and fruitfully expanded. The governance of AMR is multilevel, involving global institutions as well as national governments and local organizations. It can involve diffusion of policy instruments and ideas across regions or the globe. Powerful stakeholders, coalitions, and policy subsystems can be involved, ranging from food production and safety across pharmaceutical producers and biomedical researchers to veterinary and medical professionals and organizations. In play are vertical silos of sovereignty or organization, and horizontal networks based on interests or ideas. The five crisis lenses enable researchers to mobilize these governance elements to answer questions about how the world can effectively respond to AMR. Some pertinent themes that could be addressed are:

- Transcending barriers to global collaboration. Because of the transboundary character of AMR, many governance levels, sectors, organizations, and individuals need to be part of the solution. Yet these many actors can have reasons of their own to wait for others to act or to resist restrictions on antimicrobial uses or new avenues for access. How can AMR's global collective action problems be addressed, and how does One Health contribute? 
- Countering an uncertain future cataclysm. The AMR issue rose to global political attention between 2013 and 2016, and widespread national strategizing ensued. Yet AMR involves very long-term and uncertain consequences rather than immediate and visible focusing events, and solutions require sustained programs and resolutions of dilemmas and conflicts. How can AMR's creeping and wicked characteristics be effectively overcome?

- Forging global advocacy networks. The AMR threat shares many characteristics with other global threats, most notably climate change. Yet, unlike climate change, AMR lacks a broad and dense network of engaged NGOs, political parties, and grassroots volunteers. How can the avid AMR discourse in the scientific sphere be translated into the political and public spheres? How can a broad-based and global translational AMR network be built?

- Fair benefits and costs. AMR seems unsolvable without addressing significant behavioral patterns in HICs and major challenges to health and food safety in LMICs, now and for future generations. For most LMICs, poor access to high-quality antibiotics is a more important driver of AMR than overuse, and effective policies differ according to socioeconomic context. How can distributive justice be secured, between contexts and across generations?

Lastly, economic perspectives have been beyond the scope of this article but are highly pertinent and, hence, worthy additional scholarly attention going forward. A key focus of some AMR policy and scholarly literature is market failure (e.g., Moran, 2019; O'Neill, 2016). This includes the inability of demand and supply in markets for antimicrobials (a) to sufficiently ration such agents to inhibit microbial evolution and (b) to incentivize sufficient research and development into new agents to keep up with the same evolution. Hence, the WHO and other public health agencies have identified as key priorities governance arrangements that limit use of antimicrobials or boost research and development (WHO, OIE, \& FAO, 2015).

Externalities of antimicrobial consumption and development at the intersection of health and environmental safety have received relatively less attention so far (Destoumieux-Garzón et al., 2018). As humans and animals consume antimicrobials, the agents make their way into waterways and soil by way of their waste. In addition, as individuals and organizations use disinfectants, they repeatedly reset the environmental "petri dish." This increases AMR by killing off microbes in water and soil that are vulnerable to antimicrobials and allowing ones that have developed resistance to flourish. The AMR Global Action Plan and corresponding national action plans generally recognize that human, animal, and environmental health are interdependent (i.e., the One Health approach). Yet how antimicrobials affect the environment remains less studied and regulated (Khan et al., 2018). Thus, understanding and remedying the antimicrobial market failures related to environmental health (e.g., externalities) are important frontiers.

\section{Funding}

The project “Exploring the Policy Dynamics of Global Antimicrobial Resistance Initiatives” was funded by the Independent Research Fund Denmark (Grant no. 8019-00005B). 


\section{References}

Aguirre, E. (2017). An international model for antibiotics regulation. Food and Drug Law Journal, 72(2), 295-313.

Ahmed, S. A., Barış, E., Go, D. S., Lofgren, H., Osorio-Rodarte, I., \& Thierfelder, K. (2018).

Assessing the global poverty effects of antimicrobial resistance. World Development, 111, 148160.

Alsan, M., Schoemaker, L., Eggleston, K., Kammili, N., Kolli, P., \& Bhattacharya, J. (2017). Out-ofpocket health expenditures and antimicrobial resistance in low-income and middle-income countries: An economic analysis. The Lancet Infectious Disease, 15(10), 1203-1210.

Anomaly, J. (2010). Combating resistance: The case for a global antibiotics treaty. Public Health Ethics, 3(1), 13-22.

Ansell, C. (2019). The Protective State. Cambridge, UK: Cambridge University Press.

Ansell, C., Boin, A., \& Keller, A. (2010). Managing transboundary crisis: Identifying the building blocks of an effective response system. Journal of Contingencies and Crisis Management, 18(4), 195-207.

Barbosa, T. M., \& Levy, S. B. (2000). The impact of antibiotic use on resistance development and persistence. Harcourt Publishers Ltd. Drug Resistance Updates, 3(5), 303-311.

Beck, U. (1992). Risk society, towards a new modernity. London, UK: SAGE.

Behdinan, A., Hoffman, S. J., \& Pearcey, M. (2015). Some global policies for antibiotic resistance depend on legally binding and enforceable commitments. Journal of Law, Medicine and Ethics, 43(S3), 68-73.

Boin, A. (2004). Lessons from crisis research. International Studies Review, 6(1), 165-194.

Boin, A. (2009). The new world of crises and crisis management: Implications for policymaking and research. Review of Policy Research, 26(4), 367-377.

Boin, A., McConnell, A., \& Hart, P. (2008). Governing after crisis. Cambridge, UK: Cambridge University Press.

Boin, A., Rhinard, M., \& Ekengren, M. (2014). Managing transboundary crises: The emergence of European Union capacity. Journal of Contingencies and Crisis -Management, 22(3), 131-142.

Bosley, H., Henshall, C., Appleton, J. V., \& Jackson, D. (2018). A systematic review to explore influences on parental attitudes towards antibiotic prescribing in children. Journal of Clinical Nursing, 27(5-6), 892-905.

Broom, A., Broom, J., Kirby, E., \& Adams, J. (2016). The social dynamics of antibiotic use in an Australian hospital. Journal of Sociology, 52(4), 824-839.

Brown, B., \& Crawford, P. (2009). "Post antibiotic apocalypse": Discourses of mutation in narratives of MRSA. Sociology of Health and Illness, 31 (4), 508-524.

C40 Cities <https://www.c40.org>. (n.d.). 
Carlet, J., Pulcini, C., \& Piddock, L. J. V. (2014). Antibiotic resistance: A geopolitical issue. Clinical Microbiology and Infection, 20, 949-953.

Carpenter, R. C. (2007). Setting the advocacy agenda: Theorizing issue emergence and nonemergence in transnational advocacy networks. International Studies Quarterly, 51(1), 99120.

Centers for Disease Control. (2020). About antimicrobial resistance_<https://www.cdc.gov/ drugresistance/about.html $>$. Atlanta, GA: CDC.

Chen, L., Todd, R., Kiehlbauch, J., Walters, M., \& Kallen, A. (2017, January 13). Notes from the field: Pan-resistant New Delhi metallo-beta-lactamase-producing klebsiella pneumoniaeWashoe County, Nevada, 2016. Morbidity and Mortality Weekly Report, 66(1), 33.

Coast, J., \& Smith, R. D. (2015). Distributional considerations in economic responses to antimicrobial resistance. Public Health Ethics, 8(3), 225-237.

Cohen, M. L. (1992). Epidemiology of drug resistance: Implications for a post-antimicrobial era. Science, 257(5073), 1050-1055.

Daulaire, N., Bang, A., Tomson, G., Kalyango, J. N., \& Cars, O. (2015). Universal access to effective antibiotics is essential for tackling antibiotic resistance. Journal of Law, Medicine and Ethics, 43(S3), 17-21.

Davies, S. (2013). Annual report of the chief medical officer (Vol. 2). London, UK: Department of Health.

De Kraker, M. E. A., Stewardson, A. J., \& Harbarth, S. (2016). Will 10 million people die a year due to antimicrobial resistance by 2050 ? <https://doi.org/10.1371/journal.pmed.1002184> PLOS Medicine, 13(11).

Destoumieux-Garzón, D., Mavingui, P., Boetsch, G., Boissier, J., Darriet, F., Duboz, P., . . . Voituron, Y. (2018). The one health concept: 10 years old and a long road ahead. Frontiers in Veterinary Science, 5, 1-13.

Dixon, J., \& Macdonald, H. (2018). Globalised tuberculosis control in local worlds. Anthropology Southern Africa, 41(4), 247-256.

Filippini, M., Ortiz, L. G. G., \& Masiero, G. (2013). Assessing the impact of national antibiotic campaigns in Europe. European Journal of Health Economics, 14(4), 587-599.

Fleming, A. (1945, December 11). Penicillin_<https://www.nobelprize.org/prizes/medicine/1945/ fleming/lecture/>. Nobel lecture.

Food and Agriculture Organization. (2019). Antimicrobial resistance-what is it? <http:// www.fao.org/antimicrobial-resistance/background/what-is-it/en/> UN FAO.

Gartin, M., Brewis, A. A., \& Schwartz, N. A. (2010). Nonprescription antibiotic therapy: Cultural models on both sides of the counter and both sides of the border. Medical Anthropology Quarterly, New Series, 24(1), 85-107.

Giubilini, A. (2017). Antimicrobial resistance and antimicrobial stewardship programmes: Benefiting the patient or the population? Journal of Medical Ethics, 43(10), 653-654. 
Graham, D. W., Giesen, M. J., \& Bunce, J. T. (2019). Strategic approach for prioritising local and regional sanitation interventions for reducing global antibiotic resistance. Water, 11(1), 27.

Guzman, A. T., \& Meyer, T. L. (2010). International soft law. Journal of Legal Analysis, 2(1), 171225.

Halpern, N. E. (2009). Antibiotics in food animals: The convergence of animal and public health, science, policy, politics and the law. Drake Journal of Agricultural Law, 14(3), 401-436.

Hardin, G. (1968). The tragedy of the commons. Science, 162(3859), 1243-1248.

Hermann, M. G., \& Dayton, B. W. (2009). Transboundary crises through the eyes of policymakers: Sense making and crisis management. Journal of Contingencies and Crisis Management, 17(4), 233-241.

Hey, S. P., \& Kesselheim, A. S. (2017). Reprioritizing research activity for the post-antibiotic era: Ethical, legal, and social considerations. Hastings Center Report, 47(2), 16-20.

Hoffman, S. J., \& Ottersen, T. (2015). Addressing antibiotic resistance requires robust international accountability mechanisms. Journal of Law, Medicine and Ethics, 43(S3), 53-64.

Hoffman, S. J., \& Outterson, K. (2015). Introduction-what will it take to address the global threat of antibiotic resistance? Journal of Law, Medicine and Ethics, 43(S3), 1-6.

Hoffman, S. J., Røttingen, J.A., Frenk, J. (2015). International law has a role to play in addressing antibiotic resistance. Journal of Law, Medicine and Ethics, 43(S3), 65-67.

Högberg, L. D., Heddini, A., \& Cars, O. (2010). The global need for effective antibiotics: Challenges and recent advances. Elsevier Ltd. Trends in Pharmacological Sciences, 31(11), 509515.

Hollis, A., \& Maybarduk, P. (2015). Antibiotic resistance is a tragedy of the commons that necessitates global cooperation. Journal of Law, Medicine \& Ethics, 43(S3), 33-37.

Interagency Coordination Group. (2018, July). IACG discussion paper_<https://www.who.int/ antimicrobial-resistance/interagency-coordination-group/ IACG Future global governance for AMR_120718.pdf $>$.

Interagency Coordination Group. (2019a, April). No time to wait: Securing the future from drugresistant infections: Report to the secretary-general of the United Nations_<https:// www.who.int/antimicrobial-resistance/interagency-coordination-group/ IACG final report_EN.pdf?ua=1>.

Interagency Coordination Group. (2019b, January). Draft recommendations of the ad hoc Interagency Coordination Group on Antimicrobial Resistance_<https://www.who.int/ antimicrobial-resistance/interagency-coordination-group/ Draft IACG recommendations for public discussion 290119.pdf?ua=1 >.

Jasovský, D., Littmann, J., Zorzet, A., \& Cars, O. (2016). Antimicrobial resistance-a threat to the world's sustainable development. Upsala Journal of Medical Sciences, 121(3), 159-164.

Jensen, C. S., Nielsen, S. B., \& Fynbo, L. (Eds). (2019). Risking antimicrobial resistance. Cham, Switzerland: Palgrave Macmillan. 
Jensen, U. T., \& Andersen, L. B. (2015). Public service motivation, user orientation, and prescription behavior: Doing good for society or for the individual user? Public Administration, 93(3), 753-768.

Kades, E. (2005). Preserving a precious resource: Rationalizing the use of antibiotics. Northwestern University Law Review, 99(2), 611-675.

Kahn, L. (2016). One Health and the politics of antimicrobial resistance. Baltimore, MD: Johns Hopkins University Press.

Kamenshchikova, A., Wollfs, P. F. G., Hoebe, C. J., Penders, J., \& Horstman, K. (2018). Complex narratives of health, stigma and control: Antimicrobial resistance screening among nonhospitalized refugees <https://doi.org/10.1016/j.socscimed.2018.07.012>. Social Science \& Medicine, 212, 43-49.

Khan, M. S., Rothman-Ostrow, P., Spencer, J., Hasan, N., Sabirovic, M., Rahman-Shepherd, A., et al. (2018). The growth and strategic functioning of One Health networks: A systematic analysis. Lancet Planet Health, 2, e264-e273.

Kingdon, J. W. (2014). Agendas, alternatives, and public policies (2nd ed.). Essex, UK: Pearson Education.

Klein, E. Y., Van Boeckel, T. P., Martinez, E. M., Pant, S., Gandra, S., \& Levin, S. A. (2018). Global increase and geographic convergence in antibiotic consumption between 2000 and 2015. Proceedings of the National Academy of Sciences of the United States of America, 115(15), E3463-E3470.

Laxminarayan, R. (2016). Trans-boundary commons in infectious diseases. Oxford Review of Economic Policy, 32(1), 88-101.

Laxminarayan, R., Duse, A., Wattal, C., Zaidi, A. K., Wertheim, H. F., Sumpradit, N., . . Cars, O. (2013). Antibiotic resistance-the need for global solutions. The Lancet Infectious Diseases, 13(12), 1057-1098.

Laxminarayan, R., \& Malani, A. (2007). Extending the cure: Policy responses to the growing threat of antibiotic resistance. London, UK: Earthscan.

Laxminarayan, R., Matsoso, P., Pant, S., Brower, C., Røttingen, J.-A., Klugman, K., \& Davies, S. (2016). Access to effective antimicrobials: A worldwide challenge. The Lancet, 387(10014), 168175.

Levin, K., Cashore, B., Bernstein, S., \& Auld, G. (2012). Overcoming the tragedy of super wicked problems: Constraining our future selves to ameliorate global climate change. Policy Sciences, 45(2), 123-152.

Littmann, J., \& Viens, A. M. (2015). The ethical significance of AMR. Public Health Ethics, 8(3), 209-224.

McConnell, A. (2003). Overview: Crisis management, influences, responses and evaluation. Parliamentary Affairs, 56(3), 363-409. 
Millar, M. (2011). Can antibiotic use be both just and sustainable . . or only more or less so? Journal of Medical Ethics, 37(3), 153-157.

Moran, D. (2019). A framework for improved one health governance and policy making for antimicrobial use <https://gh.bmj.com/content/4/5/e001807>. British Medical Journal of Global Health, 4(5), 1-6.

Naylor, N. R., Atun, R., Zhu, N., Kulasabanathan, K., Silva, S., Chatterjee, A., \& Robotham, J. V. (2018). Estimating the burden of antimicrobial resistance: A systematic literature review. Antimicrobial Resistance \& Infection Control, 7(1), 58.

Nerlich, B. (2009). "The post-antibiotic apocalypse" and the "war on superbugs": Catastrophe discourse in microbiology, its rhetorical form and political function. Public Understanding of Science, 18(5), 574-590.

O’Neill, J. (2016). Tackling drug-resistant infections globally: Final report and recommendations_<https://amr-review.org/sites/default/files/

160518 Final\%20paper with\%20cover.pdf $>$.

Okeke, I. N., Laxminarayan, R., Bhutta, Z. A., Duse, A. G., Jenkins, P., O’Brien, T. F., . . Kugman, K. P. (2005). Antimicrobial resistance in developing countries. Part I: Recent trends and current status. Lancet Infectious Disease, 5(8), 481-493.

Okhravi, C., Callegari, S., \& McKeever, S., (2018). Simulating market entry rewards for antibiotics development. Journal of Law, Medicine and Ethics, 46(S1), 32-42.

Olson, M. (1965). The logic of collective action, public goods and the theory of groups. Harvard Economic Studies Vol. 124. Cambridge, MA: Harvard University Press.

Ostrom, E. (2010). Polycentric systems for coping with collective action and global environmental change. Global Environmental Change, 20(4), 550-557.

Padiyara, P., Inoue, H., \& Sprenger, M. (2018). Global governance mechanisms to address antimicrobial resistance. Infectious Diseases: Research and Treatment, 11(11), 1-4.

Podolsky, S. H. (2018). The evolving response to antibiotic resistance (1945-2018). Palgrave Communications, 4(124), 1-8.

Poushter, J., \& Huang, C. (2019, February 10). Climate change still seen as the top global threat, but cyberattacks a rising concern< <https://www.pewresearch.org/global/2019/02/10/globalthreats-2018-acknowledgments/>. Pew Research Center.

Rizvi, Z., \& Hoffman, S. J. (2015). Effective global action on antibiotic resistance requires careful consideration of convening forums. Journal of Law, Medicine and Ethics, 43(S3), 73-78.

Rochford, C., Sridhar, D., Woods, N., Saleh, Z., Hartenstein, L., Ahlawat, H., . . Davies, S. (2018). Global governance of antimicrobial resistance. The Lancet, 391(10134), 1976-1978.

Rochford, C., Sridhar, D., Woods, N., Saleh, Z., Hartenstein, L., Ahlawat, H., . . . Cassels, A. (2018). Global governance of antimicrobial resistance. The Lancet, 391(10134), 1976-1978.

Rollin, B. (2001). Ethics, science, and antimicrobial resistance. Journal of Agricultural and Environmental Ethics, 14(1), 29-37. 
Rubin, O. (2018). Natural hazards and voting behavior <https://doi.org/10.1093/acrefore/ 9780199389407.013.323 . In Oxford research encyclopedia of natural hazard science. Oxford, UK: Oxford University Press.

Sakeena, M. H. F., Bennett, A. A., \& McLachlan, A. J. (2018). Non-prescription sales of antimicrobial agents at community pharmacies in developing countries: A systematic review. International Journal of Antimicrobial Agents, 52(6), 771-782.

Shishlov, I., Morel, R., \& Bellassen, V. (2016). Compliance of the parties to the Kyoto Protocol in the first commitment period. Climate Policy, 16(6), 768-782.

Smith, R. D., Coast, J., Millar, M. R., Wilton, P., \& Karcher, A. M. (2001). Interventions against antimicrobial resistance: A review of the literature and exploration of modelling cost effectiveness. Geneva, Switzerland: Global Forum for Health Research.

So, A. J., Byarugaba, D. K., Amábile-Cuevas, C. F., Hsueh, P.-R., Kariuki, S., \& Okeke, I. N. (2010). Antimicrobial resistance in developing countries, New York, US: Springer Verlag.

Spellberg, B., Bartlett, J. G., \& Gilbert, D. N. (2013). The future of antibiotics and resistance. New England Journal of Medicine, 368(4), 299-302.

United Nations Framework Convention on Climate Change [UNFCCC]. (n.d.). Admitted NGOs_<https://unfccc.int/process/parties-non-party-stakeholders/non-party-stakeholders/ admitted-ngos/list-of-admitted-ngos $>$.

United Nations General Assembly. (2015, 25 September). Transforming our world: the 2030 Agenda for Sustainable Development_<https://www.un.org/ga/search/view_doc.asp?symbol=A/

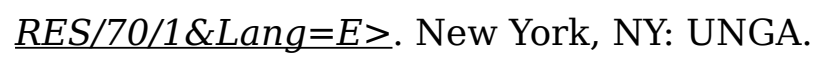

United Nations General Assembly. (2016, September 22). Political declaration of the high-level meeting of the General Assembly on antimicrobial resistance. New York, NY: UNGA.

Weingart, P., Engels, A., \& Pansegrau, P. (2000). Risks of communication: Discourses on climate change in science, politics, and the mass media_<https://journals.sagepub.com/doi/ 10.1088/0963-6625/9/3/304>. Public Understanding of Science, 9(3), 261-283.

Wendt, A. (1994). Collective identity formation and the international state. American Political Science Review, 88(2), 384-396.

West-Oram, P. G. N., \& Buyx, A. (2017). Global health solidarity. Public Health Ethics, 10(2), 212224.

World Health Organization. (2015, November 16). WHO multi-country survey reveals widespread public misunderstanding about antibiotic resistance_<https://www.who.int/newsroom/detail/16-11-2015-who-multi-country-survey-reveals-widespread-public-misunderstandingabout-antibiotic-resistance $>$. News release.

World Health Organization. (2019). UN Interagency Coordination Group on antimicrobial resistance $\leq$ https://www.who.int/antimicrobial-resistance/interagency-coordination-group/en/ $>$. 
World Health Organization, Food and Agriculture Organization, \& World Organization for Animal Health. (2015). Global action plan on antimicrobial resistance. Geneva, Switzerland: The World Health Organization.

World Health Organization, Food and Agriculture Organization, \& World Organization for Animal Health. (2018). Monitoring global progress on addressing antimicrobial resistance: Analysis report of the second round of results of AMR country self-assessment survey 2018. Geneva, Switzerland: WHO.

Wu, Z. (2017). Balancing food security and AMR. A review of economic literature on antimicrobial use in food animal production. China Agricultural Economic Review, 9(1), 14-31.

Zanders, P. Z., \& A. E. Smithson. (2011). Ensuring the future of the biological weapons convention. The Nonproliferation Review, 18(3), 479-487.

Zubair, M., \& Hussain, T. (2018). Attitude of the health care professionals towards understanding the issue of antimicrobial resistance. Value in Health, (21), S95.

\section{Related Articles}

Infectious Disease as a Foreign Policy Threat 


\section{University Library}

\section{- M M I N E R VA A gateway to Melbourne's research publications}

Minerva Access is the Institutional Repository of The University of Melbourne

Author/s:

Baekkeskov, E;Rubin, O;Munkholm, L;Zaman, W

Title:

Antimicrobial Resistance as a Global Health Crisis

Date:

2020

Citation:

Baekkeskov, E., Rubin, O., Munkholm, L. \& Zaman, W. (2020). Antimicrobial Resistance as a Global Health Crisis. Stern, E (Ed.). Oxford Encyclopedia of Crisis Analysis, (1), Oxford University Press.

Persistent Link:

http://hdl.handle.net/11343/253873 